\title{
Significance of Stable Crack Extension to Fatigue Crack Growth
}

\author{
R Sunder ${ }^{1}$ \\ ${ }^{1}$ Bangalore Integrated System Solutions Pvt Ltd
}

August 1, 2021

\begin{abstract}
A long-overlooked aspect of fatigue crack growth is the potential contribution to it, of stable crack extension (SCE). Reduction in specimen size and increase in magnitude of cyclic loading will induce increased contribution of SCE. SCE as a load interaction effect is manifest in disproportionately high crack extension due to periodic overloads. SCE can exceed by more than an order of magnitude estimates of crack growth from the da/dN versus DK relationship. Simple equations are proposed to account for SCE in fatigue crack growth. A numerical analysis is performed to characterize the significance of SCE to constant amplitude and variable amplitude fatigue crack growth.
\end{abstract}

\section{Hosted file}

StableCrackGrowth.docx available at https://authorea.com/users/302203/articles/532349significance-of-stable-crack-extension-to-fatigue-crack-growth 